\title{
La vinculación histórica de la cuestión kurda con el Orden Mundial: del Tratado de Sèvres a la Pax Americana ${ }^{1}$ The World Order and the Kurdish Question: a historical footprint from the Treaty of Sèvres to the Pax Americana. \\ Jaime ISLA LOPE \\ Universidad Nacional Autónoma de México \\ jisla@prodigy.net.mex \\ https://orcid.org/0000-0002-7582-8625 \\ Recibido 18/09/2019. Revisado y aceptado para publicación 13/12/2019
}

Para citar este artículo: Jaime ISLA LOPE (2019), "La vinculación histórica de la cuestión kurda con el Orden Mundial: del Tratado de Sèvres a la Pax Americana" en Revista de Estudios Internacionales Mediterráneos, 27, pp. 11-23.

Para acceder a este artículo: https://doi.org/10.15366/reim2019.27.002

\section{Resumen}

El artículo sintetiza los eventos internacionales más relevantes desde el surgimiento del nacionalismo kurdo en el siglo XIX hasta la consolidación de la zona autonómica de Rojava de 2014. En la primera parte se resalta el contexto internacional en el que el Imperio Otomano abandona su organización estatal tradicional en favor de la implementación de reformas liberales provenientes del orden mundial. En la segunda parte, se analiza el surgimiento de un nuevo orden hegemónico al finalizar la Primera Guerra Mundial y de cómo acabó el sueño de un Kurdistán independiente. En la tercera parte se discute la forma en que la población kurda quedó repartida en diferentes Estados del Medio Oriente y finalmente, se observa cómo la hegemonía estadounidense en el Medio Oriente no fue favorable a los kurdos, sino hasta después a la invasión de Iraq en 2003, explicando el protagonismo kurdo en el siglo XXI.

Palabras clave: kurdos/ orden mundial/ nacionalismo kurdo/ orden regional/ Medio Oriente/

\section{Abstract}

This paper synthesizes the most relevant international events from the emergence of Kurdish nationalism in the 19th century to the consolidation of the Autonomous Region of Rojava in 2014. The first section highlights the international context in which the Ottoman Empire leaves its organization traditional government in favor of the implementation of liberal reforms coming from the world order. In the second part, the emergence of a new world order at the end of the First

\footnotetext{
${ }^{1}$ Este artículo ha sido posible gracias al apoyo del PAPIIT IN305119 "Sectarismo y Justicia Social en el Medio Oriente del siglo XXI financiado por la DGAPA".
} 
World War is analyzed as well as how the dream of an independent Kurdistan was eroded. The third part, discusses the way in which the Kurdish population was distributed in different states of the Middle East and finally, it is observed how the American hegemony in the Middle East was not favorable to the Kurds until the invasion of Iraq in 2003 , explaining the Kurdish prominence in the 21st century.

Keywords: Kurds/ World Order/ Kurdish nationalism/ regional order/ Middle East/

\section{Introducción}

Enlazar la cuestión kurda con la disciplina de las Relaciones Internacionales no ha resultado tan sencillo en virtud de que la mayoría de sus enfoques parten de la idea del Estado como el actor principal que interactúa en dicho ámbito. Los kurdos, al carecer de un Estado, a pesar de constituir la minoría étnica más importante de Medio Oriente, han permanecido en gran medida relegados en el contexto internacional. Desde luego, lo anterior no significa que su lucha haya carecido de fundamentos legítimos o que haya constituido una serie de episodios esporádicos en la historia de los países de la región, como algunos pudieron haber pensado hasta no hace mucho tiempo.

En ese sentido, el presente trabajo se limita a resaltar los principales acontecimientos históricos en los que la causa kurda ha mantenido un protagonismo relevante en el ámbito internacional. Consideramos que dicha relevancia se deriva básicamente de dos motivos. En primera instancia, porque, precisamente, la inexistencia de un Estado kurdo independiente ha estado vinculada históricamente a decisiones que han provenido directa o indirectamente del orden mundial; $y$, en segundo, debido a que la mayoría de la literatura elaborada sobre la problemática kurda, si bien profundiza de manera destacada en su problemática interna, pocas veces ha sido conectada apropiadamente con el orden internacional, el que, excepto por algunos acontecimientos recientes, casi siempre les ha resultado hostil.

Por lo anterior, debo aclarar, que el desarrollo del presente trabajo se ha ceñido lo más estrictamente posible a lo internacional. Conscientemente, y con el propósito de resaltar dicho ámbito, se ha evitado, en lo posible, inmiscuirse en la problemática interna de los kurdos, tanto en sus interrelaciones y su dinámica política y social de pueblo separado por diversas fronteras como en sus relaciones con los países en los que constituyen una minoría. El análisis de dichos asuntos internos constituirá la cuestión central de los demás trabajos incluidos en el presente volumen. Así pues, en el enfoque internacional que se propone, se parte metodológicamente de la idea que constituye un error pensar que todos los sistemas interestatales han sido iguales a través de la historia y de que existen diferencias cualitativas entre un orden mundial y otro. Estas diferencias generan marcos de referencia que utilizaremos a lo largo del análisis.

En su contenido, el artículo sintetiza los procesos internacionales más relevantes desde el surgimiento del nacionalismo kurdo en el siglo XIX hasta la consolidación de la zona autonómica de Rojava en Siria en 2014. En el primer apartado, se destaca el contexto internacional en el que el Imperio Otomano se encontró con la necesidad de abandonar su organización estatal tradicional en favor de la implementación de reformas liberales procedentes de la presión ejercida por el orden mundial liberal liderado por Gran Bretaña (Cox, 1987: 111-150). Estos cambios, como se explica, incidieron decisivamente en el surgimiento del nacionalismo kurdo y en su posterior exigencia de un Estado independiente en los foros internacionales de la época. En segundo lugar, se analiza el surgimiento del nuevo orden mundial surgido al finalizar la Primera Guerra Mundial (Cox, 1987: 151-164) y de cómo el fracaso del Tratado de Sèvres acabó con el sueño de un Kurdistán independiente. En la tercera parte, se debate sobre la implantación del nuevo orden regional estatal en el Medio Oriente implantado por Inglaterra y Francia y la forma en que la población kurda quedó repartida en diferentes países. Finalmente, se constata cómo la hegemonía de los Estados Unidos implantada en la región después de la Segunda Guerra Mundial (Cox, 1987: 
211-218) tampoco fue favorable a la causa kurda, sino hasta después de la invasión de Iraq en 2003 y de la manera en que el debilitamiento del orden estatal regional explica el protagonismo kurdo en el siglo XXI.

\section{El surgimiento del nacionalismo kurdo y su contexto internacional}

Históricamente los kurdos constituyen un grupo étnico y lingüístico milenario que ha habitado las zonas montañosas en las que confluyen los territorios de Turquía, Irán, Iraq y Siria. El Kurdistán, como se le denomina a esta región, fue islamizado desde las invasiones árabe musulmanas del siglo VII, aunque sin perder su lengua e identidad a pesar de estar divididos en numerosos principados. Durante las siguientes centurias, se desarrollaron en este territorio diferentes dinastías kurdas locales que gozaron de una libertad relativa, si bien nunca pudieron unificar políticamente al Kurdistán. No fue sino hasta la consolidación del Imperio Otomano en el siglo XV que el Kurdistán fue ocupado y fragmentado por primera vez entre dos Estados, el otomano y el persa. Debe destacarse que, en la parte otomana, en la que permanecería la mayoría tanto del del territorio como de la población kurda, las wilayas o provincias kurdas mantuvieron una amplia autonomía hasta el siglo XIX. No debemos olvidar que el Imperio Otomano constituyó, hasta dicho siglo, un Estado pluriétnico en el que las minorías gozaban de un estatuto de protección especial a través del sistema millet el cual regulaba a las distintas comunidades religiosas y étnicas a las que se les permitía mantener su identidad y sus leyes a cambio de sumisión y del pago de impuestos (Sierra, 2002: 89). Dicho sistema aseguraba un control indirecto del Imperio sobre las distintas comunidades a través de líderes religiosos que actuaban como intermediarios.

Sin embargo, desde el último cuarto del siglo XVIII los turcos otomanos empezaron a sufrir una serie de severas derrotas militares, principalmente frente a Rusia, la que a partir de 1774 inició un proceso de expansión territorial a costa de los otomanos, y que, junto con la invasión napoleónica a Egipto en 1798, visibilizaron la fragilidad del Imperio Otomano frente a Europa. Estas derrotas, junto con la permanente presión diplomática ejercida por Inglaterra, persuadieron al régimen de la necesidad de cambiar en alguna forma la organización interna del Imperio. De esta manera, el gobierno de Estambul adoptó, sin oponer mayor resistencia a las influencias provenientes del orden mundial, una serie de reformas de tipo liberal conocidas primeramente como Nizam el Yedid (El Nuevo Orden) y posteriormente con el nombre de Tanzimat (Isla, 1976: 55-58).

Las reformas antes referidas tuvieron como principal propósito fortalecer política y administrativamente al Estado otomano hacia el interior, para que, hacia el exterior, Estambul pudiera ajustar su funcionamiento militar, económico y comercial a las necesidades del orden mundial liberal impuesto por Gran Bretaña. Esta estructura histórica internacional, mejor conocida en el ámbito diplomático como Pax Britannica, se refiere al lapso durante el cual este Imperio controló la mayor parte de las principales rutas navales, lo que lo llevó a encabezar un período de expansión económica y comercial que le permitió regular las relaciones internacionales a nivel global, al menos durante gran parte del siglo XIX (Isla, 2018a). En sí, las reformas otomanas se referían a un proceso de centralización del poder estatal con el propósito de garantizar su supervivencia en el contexto internacional. Lo relevante, en torno a la cuestión kurda que nos ocupa, es que una de las principales consecuencias de este proceso de centralización política y administrativa conllevó al abandono del antes mencionado sistema millet, con lo que las distintas minorías étnicas y lingüísticas comenzaron a desarrollar paulatinamente movimientos nacionalistas a lo largo y ancho del Imperio.

El resurgimiento de una identidad kurda inconforme con las medidas tomadas por el Sultán de Estambul fue casi inmediato a la implementación de las primeras reformas otomanas de principios 
del siglo XIX. Desde ese momento, el nacionalismo kurdo comenzó a involucrarse en constantes conflictos y desencuentros con el centralismo de Estambul, manifestando su resistencia a los procesos de homogeneización y control que atentaban contra su identidad.

Empero, a pesar de la resistencia y de los constantes enfrentamientos con el poder otomano, el incipiente nacionalismo kurdo no consiguió cristalizar en un movimiento independentista durante el resto de la existencia de dicho Imperio, debido principalmente a las características tribales y sectarias de la sociedad kurda del siglo XIX. Por un lado, la división tribal impidió, desde ese entonces, la concepción de un Kurdistán unificado, mientras que, por el otro, el sectarismo islámico sunita provocó que la mayoría de las fuerzas sociales kurdas continuaran leales al discurso panislamista predicado por Estambul como recurso para salvar al Imperio hasta bien entrado el siglo XX durante su etapa terminal. En otras palabras, los jefes tribales kurdos fueron permanentemente cooptados y divididos por Estambul mediante la manutención de privilegios especiales heredados del sistema millet, mientras que, de manera sectaria, otras poblaciones kurdas, al igual que los súbditos árabes del Imperio, se alinearon con el discurso de los nacionalistas turcos. En el caso árabe, el rompimiento con Estambul se dio en 1916 con la famosa revuelta comandada por el Jerife Husein de La Meca, mientras que los kurdos, en su gran mayoría, prolongaron su lealtad y apoyo al nacionalismo turco comandado por Kemal Ataturk, incluso después de terminada la guerra en contra de la ocupación de Anatolia por las potencias europeas cristianas (Mojal, 2019: 4-6).

Lo anterior, sin embargo, no impidió que en ciertos sectores y de manera paralela al ascenso del nacionalismo turco, se desarrollara un nacionalismo entre las elites kurdas que vivían principalmente en Estambul. Sobre todo, tras la revolución de los Jóvenes Turcos de 1908 aparecieron en esa ciudad asociaciones políticas y culturales kurdas, así como la publicación de un periódico en esa lengua que, de manera conjunta, centraban sus esfuerzos en torno a resaltar la existencia y potencialidad de la nación kurda. No obstante, todas estas manifestaciones nacionalistas fueron prohibidas desde 1909, e incluso, las poblaciones kurdas fueron reprimidas brutalmente por el nuevo régimen turco. Esta represión constituyó un argumento fundamental por el que después del desmantelamiento del Imperio, al final de la Primera Guerra Mundial, fueran los miembros de estas elites kurdas urbanizadas las que, en gran medida, promovieran con gran fuerza la idea de un Kurdistán independiente.

Los nacionalistas kurdos no dudaron en fundamentar su propuesta en el principio de autodeterminación de los pueblos contenido en los Catorce Puntos promulgados por el presidente Woodrow Wilson. Sus representantes se trasladaron a Paris y participaron en las negociaciones de paz entre el Imperio Otomano y la Triple Entente, logrando finalmente que dicha propuesta fuese incluida en el Tratado de Sèvres del 10 de agosto de 1920. Dicho tratado, en su artículo 62, contemplaba la creación de un Estado kurdo autónomo. Dicho Estado debería estar localizado en la parte oriental de Anatolia al sur de un pretendido Estado armenio, cuya creación también estaba contemplada en el tratado. En el mismo documento se preveía que, posteriormente, los kurdos de la región de Mosul, que habían quedado bajo la ocupación británica después de la guerra, podrían, en su momento, sumarse al nuevo Estado kurdo.

\section{El nuevo orden mundial y el fracaso del Tratado de Sèvres}

La razón principal por la que el Tratado de Sèvres nunca fue ratificado por las potencias participantes puede atribuirse, en gran medida, al retraso con que se llevaron a cabo sus negociaciones. Debe señalarse que dicha tardanza se generó primordialmente a partir de asuntos relacionados con la política mundial de la época. Ante todo, las negociaciones dependieron en última instancia de la difícil, pero también tardía consolidación del orden mundial estructurado por las potencias vencedoras después de la guerra. Lo que primero llama la atención con respecto a este asunto es el espacio de tiempo transcurrido entre la rendición otomana y la firma del tratado. El Imperio aceptó su derrota mediante el Armisticio de Mudros celebrado el 30 de 
octubre de 1918, sin embargo, los representantes de los vencidos no fueron obligados a firmar el tratado de paz y sus condiciones, en Sèvres, como se mencionó anteriormente, sino hasta el 10 de agosto de 1920. Cabe señalar, que este período de casi dos años evidentemente fue más que suficiente para cambiar la correlación de fuerzas, las cuales resultaban sumamente desfavorables para Estambul inmediatamente después de las actividades bélicas.

En dicho sentido, no debe soslayarse, que fue básicamente la dinámica que tomaron los acontecimientos relacionados con otros asuntos internacionales, considerados de mayor relevancia, los que fueron relegando el asunto relacionado con la firma del convenio de paz con el Imperio Otomano (Anderson, 1966: 361-364). En primer término, debemos destacar que los aliados estuvieron, durante la mayor parte de 1919, mucho más centrados en las negociaciones del Tratado de Versalles que en el Tratado de Sèvres. La prioridad era sin duda la paz con Alemania, considerada su principal enemigo durante el conflicto. Incluso, después de la firma del primero, las cuestiones relacionadas con su aplicación práctica, especialmente las que se referían a las reparaciones de guerra por parte de Alemania, siguieron ocupando gran parte de la atención diplomática.

En segundo lugar, la división del Imperio Austro Húngaro y la redefinición de las fronteras entre los países de la península de los Balcanes se convirtieron en otro asunto que absorbió gran parte de los esfuerzos diplomáticos de la época, y que, también, tuvo preponderancia sobre el acuerdo con los turcos. No debemos olvidar que fue la explosiva situación en dicha península, derivadas de las diferentes pugnas nacionalistas, inspiradas en gran medida por los movimientos pangermanista y paneslavista, las que encendieron finalmente la mecha de la gran conflagración bélica.

Aunque, finalmente, de acuerdo con Anderson (1966: 361-365), lo que más retrasó las negociaciones con Estambul después de la terminación del conflicto, fue una cuestión atribuible a la ilusoria esperanza consistente en que Estados Unidos pudieran aceptar la administración de un mandato, proveniente de la flamante Sociedad de Naciones, sobre el supuesto nuevo Estado de Armenia, cuya creación, como se mencionó, ya se había acordado hipotéticamente entre las potencias vencedoras. Pero no fue sino hasta mediados de mayo de 1919, después de muchas discusiones sobre la participación de Estados Unidos en torno a la ocupación de Turquía, que el presidente $\mathrm{W}$. Wilson aceptó de palabra el mandato sobre Armenia, siempre y cuando éste estuviera sujeto a la aprobación del Senado norteamericano. Aprobación que fue denegada por el Congreso de dicho país, al no aceptar, incluso, cualquier responsabilidad norteamericana en el Medio Oriente. Esto último, ocurrió hasta junio de 1920, por lo que no fue, sino hasta después de conocerse esa decisión, que se programaron las negociaciones de Sèvres con los delegados turcos, casi dos años después de la rendición.

De esta manera, factores provenientes de la arquitectura del nuevo orden mundial incidieron en la evolución de los acontecimientos regionales, que, a su vez, impidieron una rápida imposición de condiciones al gobierno derrotado de Estambul. Durante este período de veinte meses entre Mudros y Sèvres se desarrolló un gran cambio en la correlación de las fuerzas políticas hacia el interior de Anatolia. Desde el fin de la guerra resultó evidente que el gobierno otomano que se rindió a los aliados en Mudros era débil, pero se debilitó aún más durante los meses siguientes frente al surgimiento y consolidación del nuevo movimiento nacionalista turco. El desembarco de tropas griegas en Esmirna en mayo de 1919 transformó la apatía y el cansancio de la población turca en un movimiento unificado de resistencia frente a la invasión helénica. El movimiento comandado por Mustafá Kemal tuvo de inmediato un crecimiento sorprendente, pues para septiembre de ese año ya había unificado a toda Anatolia e informaba a los países aliados que el 
gobierno de Estambul no era más el representante de Turquía. En realidad, a partir de ese momento, las fuerzas nacionalistas contaron con la suficiente fortaleza para rechazar los términos impositivos del Tratado de Sèvres, el cual, por cierto, no sería elaborado sino hasta el año siguiente. Más aún, para diciembre de 1919 se celebraron elecciones para la renovación del parlamento turco, comicios en los que los nacionalistas ganaron la batalla electoral que les otorgó el control político sobre Anatolia. Cada vez era más claro para británicos y franceses que su poder naval ya no era suficiente para controlar Turquía y que sólo mediante una operación militar a gran escala podrían derrotar a Mustafá Kemal y a sus seguidores. Cabe señalar, que desde un principio el movimiento nacionalista demandó el reconocimiento de los aliados al principio de integridad del territorio turco, lo que implicó, de hecho, abandonar los esfuerzos diplomáticos para la creación de los Estados armenio y kurdo en el territorio de Anatolia.

El sueño de un Kurdistán independiente impulsado por las elites nacionalistas kurdas quedó relegado. Quedaba claro que el principio de autodeterminación de los pueblos, en abstracto, era una cosa, y otra muy diferente lo era la viabilidad para crear estos Estados independientes para las minorías étnicas y lingüísticas de Medio Oriente. Incluso, sobre el terreno, esto no resultaba sencillo, debido a que en los territorios que habitaban, las poblaciones estaban sumamente mezcladas; además de que, para esa época, no existía información precisa sobre la composición étnica y lingüística sobre dichas minorías en las áreas que se intentaba repartir (Anderson, 1966: 363). En el caso específico de los kurdos de Anatolia, los sectores tribales y sectarios más conservadores de dicha sociedad se interesaron más en la protección de sus propios intereses que en un incierto proyecto independentista. Al mismo tiempo, tanto Gran Bretaña como Francia, bajo el amparo de los acuerdos Sykes Picot, se dedicaban a la tarea de diseñar el nuevo orden regional en Medio Oriente, redibujando las fronteras, que, entre otras cosas, repartían y separaban los territorios habitados por los kurdos en la región en función de sus intereses y sus mandatos.

\section{La resistencia kurda durante el período entre guerras y el nuevo orden regional}

Durante la llamada guerra de independencia turca entre 1919 y 1922 Mustafá Kemal reconoció abiertamente la kurdicidad de las provincias orientales de Turquía, llegando, incluso, a ofrecer su plena incorporación al proyecto nacionalista mediante el establecimiento de un gobierno autónomo. Sin embargo, una vez creada la nueva república y reconocida internacionalmente por el Tratado de Lausana de 1923, para Kemal fue evidente que la idea de una autonomía kurda no constituía sino un obstáculo para el establecimiento de una república moderna y secular basada en un corporativismo estatal acentuado y en una forma peculiar de planeación central de la economía. Para facilitar el desarrollo de un proyecto de esa envergadura la homogeneización de las minorías a la cultura turca era necesaria, es decir, los kurdos debían ser asimilados. Es por ello, que a partir de 1924 se prohibió la enseñanza y utilización de la lengua kurda en las escuelas. De la misma manera, fueron prohibidas todo tipo de asociaciones kurdas y de publicaciones en dicho idioma (Mojal, 2019: 7-9). Es en este contexto sumamente represivo que comenzó a desarrollarse este renovado nacionalismo kurdo en la recién fundada república de Turquía, al cual, fueron incorporándose paulatinamente, además de la población kurda urbanizada, los sectores tribales y sectarios más conservadores de dicha población, mencionados en el apartado anterior. De esta manera, durante esa misma década y en la siguiente, se generaron rebeliones violentas, entre 1925 y 1938, cuyo propósito era explícitamente expulsar a las autoridades turcas de los territorios kurdos de Anatolia. Cabe mencionar, que todas estas revueltas fueron reprimidas de manera brutal e implacable, lo que generó que el nacionalismo kurdo se diluyera de manera sustancial durante las siguientes décadas. Habría que esperar hasta después de la Segunda Guerra Mundial, durante la Guerra Fría, para que el independentismo kurdo resurgiera y fuese perceptible, una vez más, en el ámbito internacional con el desarrollo de distintos movimientos independentistas en Irán, Iraq y Turquía principalmente. 
En cuanto al resto de los territorios kurdos fuera de Anatolia, debemos señalar que su suerte estuvo ligada al parteaguas que marcó a la totalidad de la región de Medio Oriente después de la Primera Guerra Mundial con respecto a la realidad política y social que existía previamente. Es decir, con las nuevas administraciones estatales que fueron desarrolladas a partir de la colonización, pero también con la definición y delimitación territorial de los nuevos Estados y, por supuesto, con los intentos de homogeneización de sus propios ciudadanos en los nuevos países. En este sentido, se crearon toda una serie de instituciones nuevas sobre pueblos cuya identidad, en mayor o menor medida, también se intentó modificar.

En el Mundo Árabe fueron las potencias, en este caso, Inglaterra y Francia las que establecieron por primera vez las características esenciales de los nuevos Estados (Isla, 2018a: 113-115). Ante todo, los dotaron de un sistema administrativo centralizado, un sistema legal, una bandera y fronteras internacionalmente reconocidas. En algunos casos la creación de estos nuevos Estados se produjo a partir de la unificación de diversas provincias otomanas arrebatadas al Imperio. Este fue el caso específico de Iraq y Siria, lo que les otorgó un aspecto de artificialidad desde su mismo origen y que repercutió de inmediato, entre otras cosas, en una falta de homogeneidad étnica y cultural, que fue el caso de los Kurdos que habitaban en estos dos nuevos países árabes.

En el caso de Iraq, Gran Bretaña desde 1920 amplió las fronteras de la antigua Mesopotamia para crear este inusitado reino a partir de la unificación de tres provincias otomanas: Basora en el sur, habitado de manera preponderante por chiitas; Bagdad en el centro, principalmente compuesto por población sunita; y Mosul en el norte, en donde se encontraba una población de mayoría kurda (Sierra, 2005: 25). Desde un principio resultó evidente que dicha combinación manifestaba una carencia de homogeneidad entre las poblaciones de la nueva nación, lo que, como sabemos, históricamente ha dificultado la consolidación de una identidad iraquí. Identidad que, con altibajos, nunca ha sido plenamente aceptada por los distintos grupos sociales, entre los que se encuentran los kurdos de Mosul. La incapacidad del Estado para crear una identidad iraquí basada en la pluralidad étnica y sectaria obstaculizó desde un principio la creación de estructuras políticas y sociales capaces de asegurar la estabilidad y el funcionamiento del nuevo Estado. En este sentido, si bien, la presión sobre la población kurda iraquí fue menos intensa en lo que se refiere a los procesos de asimilación -como en el caso turco- puesto que no se prohibió ni el uso de la lengua kurda ni sus manifestaciones culturales, sin embargo, el Estado iraquí surgido del mandato británico no dudó en reprimir con brutalidad desmedida las primeras rebeliones kurdas iniciadas en 1931 y posteriormente en 1944.

De la misma manera, Francia, en los territorios sujetos a su mandato en el Creciente Fértil dividió la región arbitrariamente de acuerdo con sus intereses. En el caso del mandato sirio, la administración francesa seccionó este territorio en distintas unidades administrativas en coincidencia con líneas sectarias y étnicas. De esta manera, se creó una entidad drusa y otra alauita, al mismo tiempo que se diseñaron dos entidades sunitas, una de ellas alrededor de Damasco, y la otra, en torno a la ciudad de Alepo en la que quedó incluida la minoría kurda del norte de Siria, comunidad no tan numerosa en ese momento. En realidad, la población kurda de Siria aumentó considerablemente debido a la diáspora kurda provocada por la represión de Mustafá Kemal en Turquía. Por ello, a partir de 1927 las organizaciones kurdas de Siria sentían que era posible aspirar a un modelo de autonomía comparable a los que se habían otorgado a los alauitas y a los drusos desde el inicio del mandato. No obstante, esta autonomía no les fue concedida, lo que posteriormente dio motivo a la primera revuelta kurda en Siria en 1937. 
Por último, como consecuencia de acuerdos fronterizos entre Turquía y Persia al finalizar la Primera Guerra Mundial, parte del territorio de la región ocupado por los kurdos quedó incluido dentro del Estado que a partir de 1925 se llamaría Irán. El caso de los kurdos en Irán, aunque similar en muchas cuestiones a los países vecinos, de manera distinta encuadró también una variable de tipo sectaria, puesto que, desde un principio, además de los procesos de asimilación cultural al nuevo Estado iraní, los kurdos tuvieron que padecer fuertes persecuciones religiosas dentro de un país con mayoría musulmana chiita. En Irán, al igual que en Turquía, hubo resistencia a la ocupación extranjera y se concibió el establecimiento de un nuevo orden político. Al frente de esa resistencia contra la ocupación parcial de parte de su territorio -por parte de Gran Bretaña y la nueva nación bolchevique- se encontraba Reza Khan, jefe militar que aprovechó la anarquía generalizada en Persia al término de la Gran Guerra para derrocar a la dinastía Kayar e instaurar en su lugar a la dinastía Pahlevi a partir de 1925. De inmediato, el nuevo Sha aplastó toda oposición de tipo tribal o sectaria, incluyendo a la población kurda, imponiendo de esta manera un control centralizado sobre todo el territorio iraní. Asimismo, imitando el ejemplo de Mustafá Kemal, asimismo, introdujo una serie de reformas de carácter secular con el propósito de homogeneizar y asimilar a las minorías étnicas, lingüísticas y sectarias, sometiendo en este caso a las poblaciones kurdas sunitas (Sierra, 2005: 43-45.)

De alguna manera, con el orden regional impuesto por las potencias europeas a partir de los Mandatos de la Sociedad de Naciones sobre Siria e Iraq, con la consolidación del Estado iraní bajo Reza Khan y, sobre todo, con el Tratado de Lausana de 1923 que dio pie a la creación de la república de Turquía, la visión general de la nación kurda quedó reducida en el ámbito internacional a la de minorías inmersas en el ámbito de los cuatro Estados en los que hoy se encuentran. Igualmente, si bien en sus respectivos ordenes estatales los kurdos mantuvieron luchas permanentes por su identidad y sus derechos, en la esfera internacional la concepción de una nación kurda en su conjunto quedó relegada durante largo tiempo, y en su lugar, se les consideró como minorías en proceso de asimilación dentro de sus Estados. Como consecuencia, hasta la Segunda Guerra Mundial, e incluso algunas décadas después, las luchas de resistencia kurda se vieron confinadas dentro de sus espacios estatales. A estas minorías separadas estatalmente, nunca se les consideró durante el resto del siglo $\mathrm{XX}$, como parte de un movimiento general para la liberación del Kurdistán y su lucha se contempló internacionalmente como una serie de intentos secesionistas aislados que atentaban contra la estabilidad e integridad de un orden regional instituido por las grandes potencias.

\section{La Pax Americana en el Medio Oriente y la cuestión kurda}

Se conoce como Pax Americana al nuevo orden mundial aparecido inmediatamente después de la Segunda Guerra Mundial en el que Estados Unidos asumió el papel de potencia hegemónica dentro de dicho orden. Debemos señalar, en lo que respecta a la cuestión kurda, que de manera un tanto sorprendente, al finalizar la Segunda Guerra Mundial el Kurdistán iraní protagonizó un episodio que volvió a mostrar la lucha de su pueblo a nivel internacional. En sí misma, la Segunda Conflagración Mundial presentó consecuencias importantes para el mantenimiento del orden regional en el Medio Oriente. El de mayor relevancia, lo constituyó, desde el punto de vista geopolítico, el que la región pasara a ser zona de influencia de los Estados Unidos, quien heredó, principalmente de los británicos la responsabilidad hegemónica en esta parte del mundo (Isla, 2018b). En ese sentido, diversos episodios al inicio de la Guerra Fría llevaron a Washington a involucrarse directamente en la región como parte de su política de contención del comunismo. Esta política sería expresada más concretamente a partir de 1947 dentro del marco de la llamada Doctrina Truman. Con antelación a esta fecha, sin duda, una de las causas del involucramiento norteamericano en la región fue provocado por la reticencia del líder soviético José Stalin para abandonar los territorios de Irán que, junto con Inglaterra, por diversos motivos estratégicos, habían ocupado desde 1941. Durante ese episodio la población kurda de Irán, apoyada por la Unión Soviética, proclamó en 1945 la República de Mahabad que logró mantenerse como Estado 
independiente durante casi un año. Empero, al año siguiente, las fuertes presiones ejercidas por Estados Unidos consiguieron que las tropas soviéticas iniciaran su retirada de los territorios iraníes, lo que constituyó uno de los primeros éxitos de la política norteamericana en el Medio Oriente durante las escaramuzas iniciales de la Guerra Fría. Al mismo tiempo, este acontecimiento representó el fin del Estado kurdo en Irán. Inmediatamente después de la salida de las tropas soviéticas las fuerzas militares del Sha arremetieron sobre Mahabad destruyendo de raíz a la nueva república, la cual colapsó con la ocupación de las fuerzas iraníes en diciembre de 1946 (Albani, 2015). Una vez más, la lucha por la independencia kurda rindió tributo a la imposición de prioridades provenientes del orden regional e internacional.

Si bien, durante el resto de la Guerra Fría hubo una constante agitación independentista por parte de los kurdos en sus respectivos países, ésta no llegó a repercutir con claridad en las estructuras internacionales. La hegemonía norteamericana en el Medio Oriente, durante este período, se centró básicamente en dos objetivos: la contención de la Unión Soviética y la actividad comunista dentro de los países de la región; así como el control del petróleo para garantizar el suministro de este energético a las economías de los países industrializados del bloque occidental (Isla, 2018a; 148-160). En este sentido, cabe señalar, que en los países en los que habitaban los kurdos, Estados Unidos siempre prefirió privilegiar sus relaciones con los gobiernos de Ankara, Bagdad, Damasco e incluso Teherán hasta 1979, antes que arriesgar la estabilidad regional en favor de las minorías kurdas. De esta manera, los movimientos independentistas kurdos surgidos en Iraq entre 1961 y 1975; en Irán en 1979 en contra del régimen instaurado tras la revolución islámica; y en Turquía, desde 1984, con el movimiento guerrillero auspiciado por el Partido de los Trabajadores del Kurdistán (PKK), nunca consiguieron un apoyo decisivo ni de las potencias occidentales ni de parte de organismos internacionales o regionales. Incluso, sucedía lo contrario, al orden mundial le preocupaba mucho más lo que las pretensiones autonómicas kurdas podrían significar para la estabilidad del orden regional. Todavía, inclusive, tras la Guerra del Golfo de 1991, se produjo un nuevo levantamiento kurdo contra el régimen de Sadam Hussein que fue literalmente aplastado por su ejército, ante la pasividad de las fuerzas occidentales. En este sentido, debemos subrayar el restringido papel jugado por la Organización de las Naciones Unidas frente a la cuestión Kurda desde su fundación en 1945, puesto que este representa un notable ejemplo de las grandes limitaciones que ha presentado dicha Organización con respecto a los derechos de las minorías dentro de los Estados y más aún en lo que toca a los derechos humanos de todo un pueblo que se encuentra disperso en los territorios de varios países como resulta ser el caso del pueblo kurdo.

Paradójicamente, el fin de la Guerra Fría no significó la consolidación de la Pax Americana en el Medio Oriente como todo parecía indicarlo. Aunque si bien, en un principio, así lo sugerían las poderosas intervenciones norteamericanas en Afganistán e Iraq, sin embargo, su posterior desenlace no hizo sino generar muchas dudas al respecto. El fracaso a mediano plazo de la ocupación norteamericana en ambos países no consiguió sino corroborar el desastre de la "guerra contra el terrorismo" y la falacia del "Nuevo Siglo Estadounidense"(Garduño, 2016). Estos acontecimientos, entre otros, han contribuido a generar un creciente desprestigio de la política exterior de ese país en el Medio Oriente y un paulatino declive de su influencia a nivel regional.

Desde el punto de vista estatal, antes de la Primera Guerra Mundial, como ya se mencionó, los aparatos estatales en el Medio Oriente no correspondían a límites territoriales definidos. Las fronteras de los Estados surgieron vinculadas al desarrollo de los nuevos nacionalismos. Este hecho generó un intenso esfuerzo por parte de los nacientes Estados por concentrar su poder frente a la resistencia de fuerzas descentralizadoras. El caso kurdo es un claro ejemplo de como se 
dieron este tipo de tensiones durante el período de la Guerra Fría, en el que el Estado-nación se concibió como un instrumento coercitivo para ejercer control sobre las zonas periféricas ocupadas por los kurdos. Así pues, durante el siglo XX los Estados con poblaciones kurdas se embarcaron en diversos intentos de control y centralización, suprimiendo con ello a sus minorías mediante tácticas de asimilación o represión.

De esta manera, durante la Guerra Fría las elites gubernamentales de Turquía, Irán, Iraq y Siria se dieron a la tarea de construir ideologías estatales para para consolidar sus proyectos nacionales. La necesidad de conformar Estados fuertes condujo al diseño de proyectos monolíticos que paulatinamente fueron definiendo a sus poblaciones kurdas como fuerzas descentralizadoras, los gobiernos se negaron a reconocer los derechos políticos y culturales de sus comunidades y comenzaron un proceso de homogeneización para diluir la identidad kurda. Esta represión política y cultural mantuvo a los kurdos en un estado de rebelión continua durante gran parte de la Guerra Fría, por lo que se les contempló como una amenaza a la integridad territorial de los Estados en los que se encuentran. En este sentido, la consecuencia más importante de las revueltas kurdas durante este período se centró en el desarrollo gradual de una conciencia nacional y de un sentimiento de kurdidad generalizado. Como consecuencia, el nacionalismo kurdo logró adaptarse exitosamente a los distintos contextos políticos y sociales en los que se desenvuelven los pueblos kurdos. Este proceso se desarrolló con especial intensidad en la en la década de los sesenta en Iraq y de los ochenta en Turquía. Sin duda, estos acontecimientos durante el período de la Guerra Fría a nivel regional sirvieron para consolidar las bases de la identidad cultural y la movilización social de los kurdos (Castillo, 2018: 129-135).

Subsiguientemente, acontecimientos como el de la guerra Irán-Iraq de 1980-89, la invasión a Iraq de 1991, pero, sobre todo, la mencionada ocupación de este país en 2003, comenzaron a manifestar un creciente debilitamiento de los Estados en la región, el que se manifestó plenamente con el estallido de los movimientos populares árabes durante 2011. De esta manera, tanto el declive estadounidense en los asuntos regionales como el debilitamiento de los Estados autoritarios en el Mundo Árabe dieron origen, por primera vez, desde el fin de la Primera Guerra Mundial, a un entorno internacional y regional que pareció cambiar en favor de la causa kurda. De manera un tanto inadvertida, todo comenzó en 1991 cuando Estados Unidos durante su mencionada intervención en Iraq estableció una zona de exclusión aérea en el norte de este país. Esta acción, por si misma, transformó la posición de los kurdos en Iraq, al imposibilitar al gobierno iraquí continuar ejerciendo su riguroso control en la parte norte del país, como consecuencia, al año siguiente, los kurdos de Iraq lograron establecer en dicha parte el primer Gobierno Regional del Kurdistán (Castillo, 2018: 136).

Posteriormente, la invasión estadounidense a Iraq en 2003 provocó que los grupos políticos kurdos en ese país se alinearan del lado del invasor con el objetivo de conseguir una mayor autonomía tras el derrocamiento de Sadam Hussein. La fragmentación política producida por esta invasión durante los siguientes años sin duda favoreció la consolidación de la autonomía del Gobierno Regional del Kurdistán al interior de Iraq. De la misma manera, esta fragmentación política iraquí, acompañada del caos generado por la guerra civil en Siria, constituirían importantes acontecimientos que darían paso al surgimiento del nuevo ente denominado Estado Islámico, el cual llevaría a cabo la ocupación de diversos territorios aprovechando los vacíos de poder derivados del debilitamiento de ambos actores estatales. En efecto, en 2014 el Estado Islámico conquistó una porción de la Mesopotamia sirio-iraquí, lo que fue considerado como una amenaza para la población kurda de ambos países. Concretamente, la caída de Mosul en manos de este nuevo actor provocó la respuesta militar de las fuerzas kurdas, lo que, a su vez, les brindó la oportunidad de reconquistar y consolidar su territorio y de incrementar su posición como aliado estratégico de Washington (Castillo, 2018: 137). De esta manera, el Estado Islámico se constituyó en un catalizador que favoreció las condiciones regionales e internacionales para la causa kurda. 
Al mismo tiempo, el señalado debilitamiento de los actores estatales árabes durante la presente década, en este caso el de Siria, dio lugar al establecimiento de una nueva región autónoma kurda en el norte de Siria. Una vez más, el vacío de poder provocado por el retiro de las tropas sirias de las regiones kurdas en 2012 durante la guerra civil permitió la consolidación de esta zona autonómica denominada Rojava o Kurdistán occidental. Después de fuertes rivalidades internas, para el año 2014 el Partido de la Unión Democrática se constituyó en la principal fuerza política y militar kurda en Siria al declarar la autonomía y constituir los llamados cantones autónomos de Rojava. Cabe señalar, que los vínculos de este partido con el PKK turco lo enfrentaron de inmediato con el gobierno de Ankara que considera a ambas organizaciones como terroristas. Así, desde 2016, Turquía ha intervenido en el conflicto sirio tratando de evitar la consolidación del proyecto autonómico de Rojava, puesto que considera que el mismo puede inspirar la implementación de una experiencia similar en la parte kurda de Turquía. Sin embargo, Rojava ha logrado subsistir desde entonces a las presiones turcas con el apoyo estadounidense e incluso de Rusia en menor medida. En realidad, ambas potencias han utilizado a los kurdos para conseguir sus objetivos particulares en Siria. En este sentido, como bien lo señala Castillo Quiñones, "el proyecto kurdo en Siria depende en gran medida de las permanentes fluctuaciones de la política regional y de las decisiones tomadas en un futuro próximo por Estados Unidos y Rusia en lo que respecta a Siria y a una posible reestructuración en Medio Oriente" (Castillo, 2018: 139). En cuanto al ámbito regional, sin lugar a duda, Turquía representa la principal amenaza para la existencia de Rojava, para ello, baste mencionar los últimos acontecimientos relacionados con la ofensiva desarrollada por los turcos en octubre de 2019.

\section{Conclusión}

A lo largo de este trabajo se sintetizaron los acontecimientos internacionales más relevantes en el desarrollo de la cuestión kurda. En primera instancia, se destacó el contexto internacional en el que el Imperio Otomano abandonó su organización tradicional en favor de la implementación de reformas liberales provenientes del orden mundial, lo que permitió el surgimiento de dicha problemática. A continuación, se constato la manera en que la aparición de un nuevo orden mundial al finalizar la Primera Guerra Mundial acabó con el sueño de un Kurdistán independiente y de cómo la población kurda quedó distribuida en diferentes Estados del Medio Oriente. También, se observó la forma en que durante la Guerra Fría la hegemonía estadounidense en la región fue desfavorable a la causa kurda y de cómo ésta prosperó a su favor a partir de la invasión de Iraq en 2003, lo que explica de alguna manera el protagonismo kurdo durante el siglo XXI.

Cabe añadir finalmente, que en el caso kurdo debemos establecer que el peso relativo de lo internacional no ha sido siempre el mismo, sino que ha estado condicionado históricamente por las estructuras prevalecientes en los diferentes ordenes mundiales. En cuanto al interior del movimiento kurdo, nos limitaremos a mencionar que, por lo pronto, el surgimiento de Rojava ha generado la confrontación de dos proyectos organizacionales opuestos en la dinámica de este movimiento. Por un lado, el proyecto estatista neoliberal del Gobierno Regional del Kurdistán en Iraq, frente al confederalismo democrático autonómico de Rojava, confrontación que nos atrevemos sólo a mencionar, sin ahondar más en el asunto, en virtud de las repercusiones que seguramente podría tener esta cuestión en el ámbito regional en un futuro. En este sentido, me permito agregar que, sin la construcción y consolidación de un Estado kurdo independiente, será difícil contener las divisiones internas dentro del movimiento, puesto que un Estado kurdo constituiría el agente que podría activar y canalizar las potencialidades de una formación social kurda. En el presente, aunque se hable de una posible debilidad de los Estados en el ámbito 
internacional, aún es necesario considerar que existe una conexión directa entre el esfuerzo de estos por organizar a sus sociedades y su empeño por sobrevivir y perseguir sus metas en el contexto internacional.

Cabe destacar que el desarrollo tan dinámico de los acontecimientos en el Kurdistán durante el presente siglo sería impensable sin contar con la desmedida injerencia del orden mundial en Medio Oriente, la cual se manifestó abruptamente en el caso kurdo con la ocupación estadounidense de Iraq en 2003. Dicho acontecimiento, junto con la internacionalización del conflicto sirio, ha proporcionado a los kurdos una nueva oportunidad política para la consolidación de su propia identidad y de sus proyectos nacionalistas, ya sean autonómicos o independentistas. Sin embargo, a pesar del debilitamiento estatal de Iraq y Siria, que explica en gran medida la reaparición de este protagonismo kurdo en el siglo XXI, faltaría esperar si en esta ocasión, la transición hegemónica del orden mundial hacia un posible multilateralismo podría conllevar a una eventual reconfiguración política en la región, esta vez, favorable a la causa kurda.

\section{Referencias}

ALBANI, Leandro. (2015): "Mahabad: cuando el pueblo kurdo fue república", Resumen Medio Oriente, 20 de noviembre de 2015, disponoble en

http://www.resumenmediooriente.org/2015/11/20/mahabad-cuando-el-pueblo-kurdo-fuerepublica/ [consulta: 3 de septiembre de 2019].

ANDERSON, M.S. (1966): The Eastern Question: 1774-1923, A Study in International Relations, London, Macmillan.

BROWN, Carl (ed.). (2001): Diplomacy in the Middle East, The International Relations of Regional and outside Powers, London, I.B. Taurus Publihers.

BROWN, E.M. (1993): "Causes and Implications of Ethnic Conflict”, en BROWN, E.M. (ed.), Ethnic Conflict and International Security, New Jersey, Princeton University Press, pp.3-26.

CASTILLO, Juan Carlos, (2018), "Los kurdos en el escenario geopolítico del Medio Oriente pos2010: fronteras, nacionalismo y estado-nación", en GARDUÑO, Moisés (et al), Temas contemporáneos de Medio Oriente: Ensayos en honor a Luis Mesa Delmonte, México, El Colegio de México/UNAM, pp. 129-139.

CLEVELAND, William. (2000): A History of he Modern Middle East, 2nd ed., Colorado, Westview Press, Boulder.

COX, Robert. (1987): Production, Power, and World Order: Social Forces in the Making of History, New York, Columbia University Press.

DAVIDSON, Roderik, (1963): Reform in the Otoman Empire, 1856-1876, New Jersey, Princeton University Press.

EPPEL, M. (2008): "The Demise of the Kurdish Emirates: The Impact of Otoman Reforms and International Relations on Hurdistan during the First Half of the nineteenth Century", Middle Eastern Studies, 44:2, pp. 237-258. DOI: https://doi.org/10.1080/00263200701874883

GARDUÑO, Moisés. (2016): Dinámicas de poder y prácticas de resistencia en las revoluciones árabes, México, Centro de Investigaciones y Estudios en Antropología Social (CIESAS) / Casa Chata. HALLIDAY, Fred. (2005): The Middle East in International Relations: Power, Politics and Ideology, New York, Cambridge University Press.

HANIOGLU, Sûkûru. (2008): A Brief History of the Late Otoman Empire, Princeton/Oxford, Princeton University Press.

Hurewitz, J. C. (1956): Diplomacy in the Near and Middle East. A documentary record, 1535-1914 (1914-1956), Princeton, D. Van Nostrand Co.

ISLA, Jaime, (1976): "Los primeros intentos modernizadores en el Imperio Otomano", Relaciones Internacionales, núm. 13, vol. IV, abril-junio, México, UNAM, pp. 51-5.

-----------, (2018a), La injerencia histórica del orden mundial en el Medio Oriente, México, UNAM/SITESA. 
----------, (2018b) "El Medio Oriente y el orden mundial a cien años de los acuerdos Sykes-Picot", en BALLESTEROS, Carlos (coord.), Regiones internacionales. Una perspectiva transversal, México, UNAM.

LEYSENS, Anthony. (2008): The Critical Theory of Robert W. Cox: Fugitive or Guru?, New York, Palgrave Macmillan.

MCDOWALL, D. (2004): A Modern History of the Kurds, 3a ed., Nueva York, I.B. Tauris.

MOJAL, Xavier: "La cuestión kurda en Turquía: Un conflicto interminable. Parte I: orígenes del conflicto y evolución hasta el nacimiento del PKK, MENA Analisis, 2019, disponible en http://www.menanalisis.com/la-cuestion-kurda-en-turquia/ [consulta: 18 de agosto de 2019].

NATALI, D. (2005): The Kurds and the State, Syracuse, Nueva York, Syracuse University Press.

SIERRA, María de Lourdes. (2002): Introducción al estudio del Medio Oriente. Del surgimiento del Islam a la repartición imperialista de la zona, México, Facultad de Ciencias Políticas y Sociales, Universidad Nacional Autónoma de México.

---------, (2007), La influencia del factor externo en la configuración del Medio OrienteModerno y sobre sus relaciones internacionales, México, Facultad de Ciencias Políticas, UNAM. 